\title{
Learning by poster competition: A new teaching strategy in basic medical science.
}

1. MBBS, FCPS, FRCS

Professor and Principal

Ophthalmology

Sahiwal Medical College Sahiwal, Pakistan.

2. MBBS, M.Phil

Assistant Professor Physiology Sahiwal Medical College Sahiwal, Pakistan.

3. MBBS, M.Phil

Associate Professor and Head Pathology

Sahiwal Medical College Sahiwal, Pakistan.

4. MBBS, M.Phil

Assistant Professor Physiology Sahiwal Medical College Sahiwal, Pakistan.

5. MBBS, MPH

Professor and Head Community Medicine

Sahiwal Medical College Sahiwal, Pakistan.

6. MBBS, FCPS

Assistant Professor Surgery

Sahiwal Medical College Sahiwal,

Pakistan.

Correspondence Address:

Dr. Nauman Aziz

Department of Physiology

Sahiwal Medical College Sahiwal,

Pakistan.

nauman188@gmail.com

Article received on:

22/04/2020

Accepted for publication

03/07/2020
Zahid Kamal Siddiqui' ${ }^{1}$, Nauman Aziz², Raees Abbas Lail ${ }^{3}$, Hafiza Swaiba Afzal ${ }^{4}$, Rana Aamir Diwan ${ }^{5}$, Muhammad Amjad ${ }^{6}$

ABSTRACT... Objective: The objective of study was to mature Poster competition as collaborative study tool in order to define if the method of study impacts student education by analyzing student depiction in terms of fulfillment. Study Design: Analytical study. Setting: Sahiwal Medical College Sahiwal. Study Period: $20^{\text {th }}$ Feb, 2020 to $20^{\text {th }}$ March, 2020. Material \& Methods: A poster competition was held among 400 MBBS students of $1^{\text {st }}$ year to $4^{\text {th }}$ year at Sahiwal Medical College Sahiwal. Ethical consent was approved by the ethical review committee of Sahiwal Medical College Sahiwal. Hand on collective valuation was used to assess students' performance by using a questionnaire consisting of 12 questions. Different frequencies were then calculated using SPSS-20. Results: According to first part of the questionnaire students' response was calculated as frequencies and were alienated into three groups of low, medium and high scores. $81.25 \%$ of total 400 students understood the topic fully. $69.75 \%$ of the students worked in harmony and $55.75 \%$ of students preferred group activity over individual assignments. $85.25 \%$ enjoyed this learning activity while $75.25 \%$ wanted this activity to happen in future too. As far as teacher's approach was considered more than $70 \%$ of the students strongly agreed that the teachers stimulated their interest. Conclusion: The outcomes of the current study propose that concepts distributed in the way of Poster competition may increase student's aptitude to evoke info, in spite of not meaningfully influencing students' performance. Nevertheless, more studies with greater student cohorts are necessary.

Key words: $\quad$ MBBS Students, Poster Competition.

Article Citation: Siddiqui ZK, Aziz N, Lail RA, Afzal HS, Diwan RA, Amjad M. Learning by poster competition: A new teaching strategy in basic medical science. Professional Med J 2021; 28(4):572-579. https://doi.org/10.29309/TPMJ/2021.28.04.4698

\section{INTRODUCTION}

Teaching is undoubtedly the backbone of any academic institution. Subsequently, lectures don't generally get the job done to make a student of basic clinical sciences to get a handle on the key ideas and the better subtleties of the subject. ${ }^{1}$ During the conventional lectures, the capacity to focus can slip by after 10-15 mints. Accordingly, the students will have little premium or inspiration to learn it. ${ }^{2}$ Thus, lecturers of basic medical disciplines are resorting to original approaches and alterations in their teaching rehearses, additional to the old-style, educational classroom lectures, which might consist of bedside teaching, sessions, role-play, and many more.

Poster presentation in scholastics has been utilized as a technique for transmitting learning. ${ }^{3}$
Poster presentation gives the watcher a superior perspective on the theme. A decent poster is a student well-disposed and a brief apparatus to pass on information to a student. ${ }^{4}$ Posters can fill in as adjusted psyche maps for students to get the grip of the subject. ${ }^{5}$ Such learning alludes to exercises where learners utilize their abilities to plan and assemble models and in the process gain deep comprehension with respect to the significant theme. Toward the finish of the presentation, undergraduates are loaded up with a feeling of achievement and this lifts their selfconfidence. ${ }^{6}$ They likewise need to build up the flexibility for group work and camaraderie during this activity. ${ }^{7}$

Not much work has been done previously on making poster competition as a way of learning. 
We made an endeavor to utilize posters and models as a changed apparatus of educating by holding a poster rivalry, to discover how well it stirs and produces enthusiasm among students with respect to a specific point in basic medical sciences. The topics of poster competition were subject specific but not idea specific.

\section{RATIONALE OF STUDY}

The aim and goal of a poster or a model are to outwardly delineate and impart the proposed message to be passed on in an engaging, clear, and exact way. In a solitary class of 100 students, there is a wide fluctuation in knowledge, development, and inspiration levels. A few of them have significant levels of inherent inspiration for learning and they will get familiar with the subject independent of the instructing techniques. The customary technique for instructing is less inclined to oblige the requirements of students who need natural inspiration. Such candidates feel less slanted and less inspired to consider the subjects of basic medical sciences. They find the subject tremendous, unstable, and hard to learn and in addition hold; as such they think that it's hard to get a grasp on the key ideas of basic medical sciences. We attempted this investigation for the first year to fourth year MBBS undergraduates as "competition of posters" with these points:

1. To give an outward inspiration to learning and permit it to convert into characteristic inspiration during the act of making the poster.

2. To create intrigue and encourage better comprehension of the subject and of its different ideas. This would help the participants in their clinical course in later expert life, basic medical sciences being a basic piece of clinical practice.

3. To build up their initiative capacity to get ready and set forth an introduction and create trust in them in this way preparing them for better patient correspondence and patient advising in the future. This would form them into future pioneers.

4. To comprehend bunch elements of learning and soak up the team spirit through the group activity, which would assist the students with developing versatility and the capacity to change in accordance with their colleagues.
In this way, it will assist them with working in the concordance and be accommodative in their methodology helping them sometime down the road to alter and work with others.

5. To train students to be agreeable in the presence of a group of people consequently empowering those to conquer stage dread along these lines improving their character and delicate aptitudes.

6. To empower, instruct, and train them to appreciate a subject without making it an upsetting encounter. When feelings of anxiety are very high in our general public and all the more so among medical students, this strategy could be one of the approaches to diminish worry of studying, making the learning experience charming notwithstanding being educational.

7. To give them a chance to find and develop their inventive abilities, in this way consolidating creativity and learning.

\section{MATERIAL \& METHODS}

A questionnaire based analytical study was done and its approval was taken from the Ethical Review Committee, Sahiwal Medical College Sahiwal. We chose different topics from all the subjects of basic medical sciences. A formal announcement related to the "poster competition" was made in the MBBS classes 20 days in advance and competition was conducted according to following format:

1. Each MBBS class having strength of 100 students was divided into 15 groups, each group consisting of 5-7 students.

2. Each group picked their topics for posters by consulting with their respective group teachers hence decreasing the bias.

3. The division of topics was such that it included the entire portion of all the subjects of basic medical sciences taught to students of $1^{\text {st }}$ year till $4^{\text {th }}$ year MBBS.

4. On the final day, the students presented the posters and explained the models with great zeal and zest.

5. The posters were evaluated using the following parameters. - Relevance of the topic. - Scientific and technical proof. Understanding, analysis and interpretation. • 
Neatness and attractiveness. - Overall effect of presentation, audience response.

Feedback questionnaire forms were provided to all the 400 students and responses were collected on a Likert scale of 1 to 5 . Informed consent was also taken before taking the response of students. Statistical analysis was performed using SPSS version 20. Quantitative data was shown as percentage frequencies. Bar graphs were also drawn comparing students' responses for many questions regarding teachers' approach and academic atmosphere during the competition.

\section{RESULTS}

According to first part of the questionnaire students' response was calculated as frequencies and were divided into three groups of low, medium and high scores. $81.25 \%$ of total 400 students understood the topic fully. $69.75 \%$ of the students worked in harmony and $55.75 \%$ of students preferred group activity over individual assignments. Only $19.5 \%$ students felt that they had increase in confidence while $62.25 \%$ were neutral. $85.25 \%$ enjoyed this learning activity while $75.25 \%$ wanted this activity to happen in future too. As far as teacher's approach was considered more than $70 \%$ of the students agreed or strongly agreed that the teachers stimulated their interest, managed time well, encouraged them, demonstrated well and appeared enthusiastic. Majority of the students (more than 50\%) also agreed that teachers played their active part in preventing cheating during competition, clearly mentioned topics and engaged students well.

Similarly students' response was more than satisfactory about the academic atmosphere during competition. $78 \%$ of the students thought that the environment was relaxed and also session was well timed. $72.3 \%$ felt that they were comfortable and were able to concentrate well during the competition. 59.8\% felt motivated and $42 \%$ of the students were able to ask questions from the teachers whenever they wanted. However $78.5 \%$ of the students were neutral about audio visual aid during the competition.

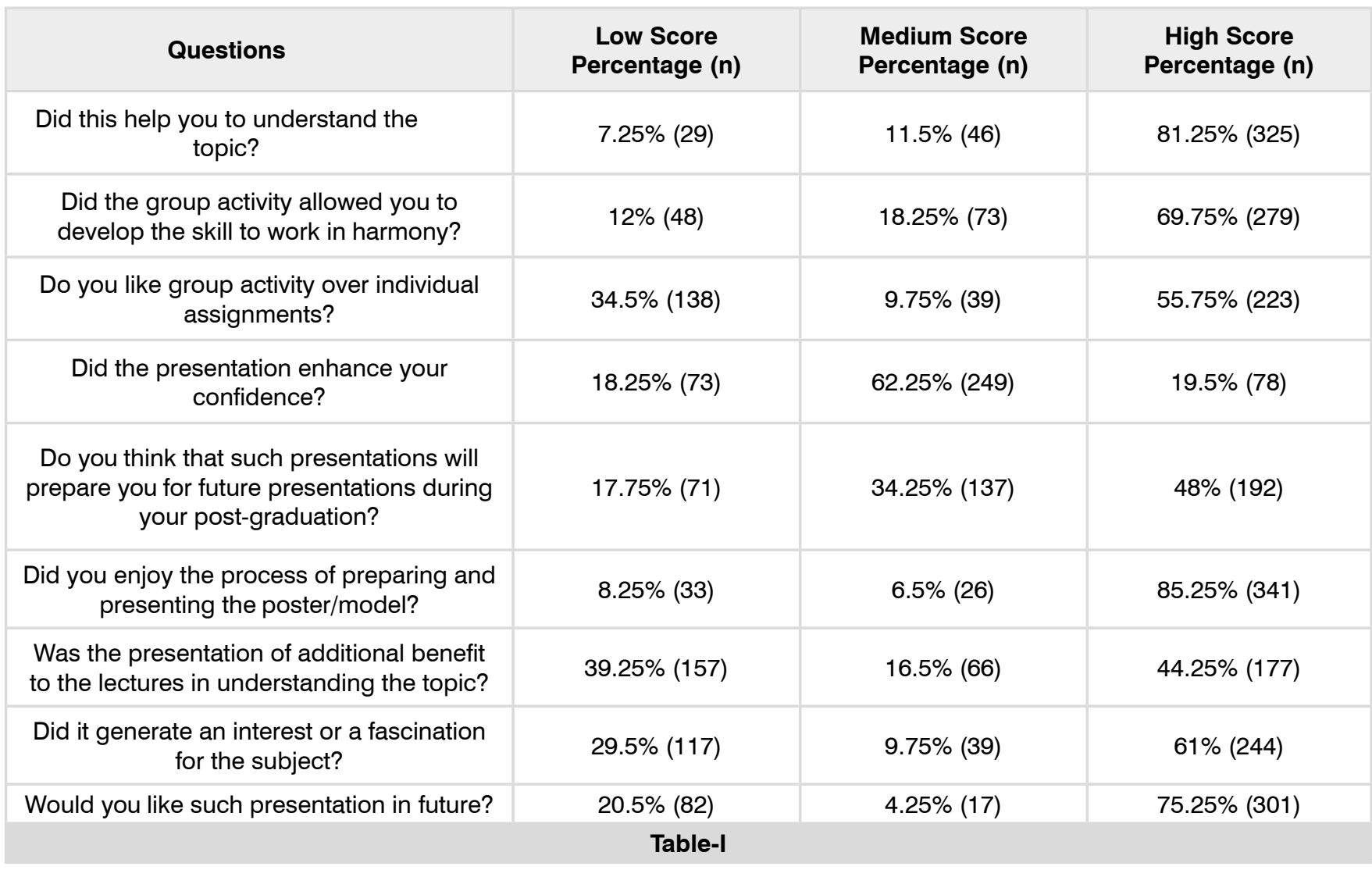




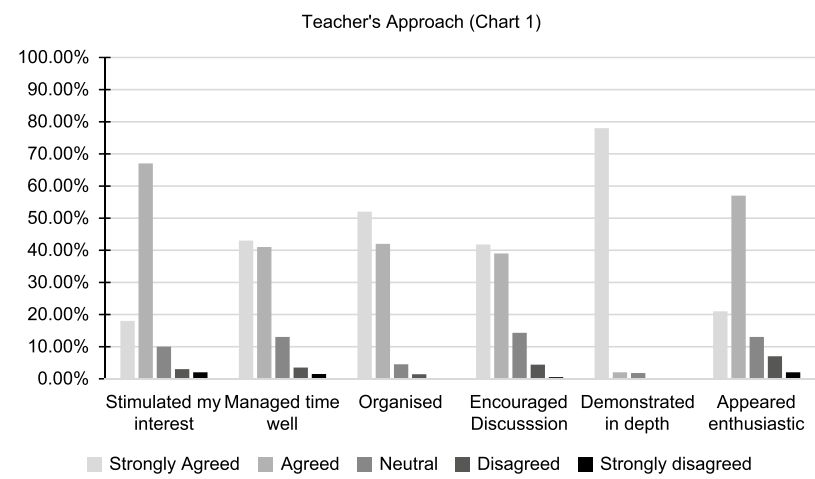

Figure-1. Teachers approach during the poster competition according to students' response on questionnaire

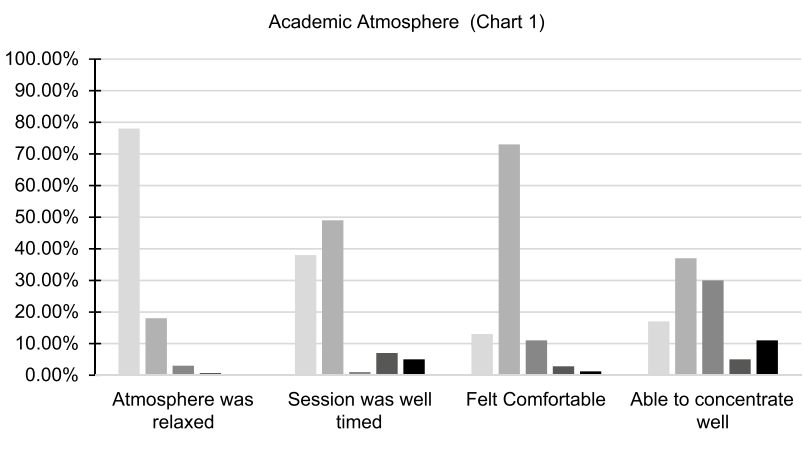

Strongly Agreed Agreed Neutral $\square$ Disagreed $\square$ Strongly disagreed

Figure-3. Academic Atmosphere during the poster competition according to students' response on questionnaire

\section{Samples of posters made by students under the supervision of Teacher}

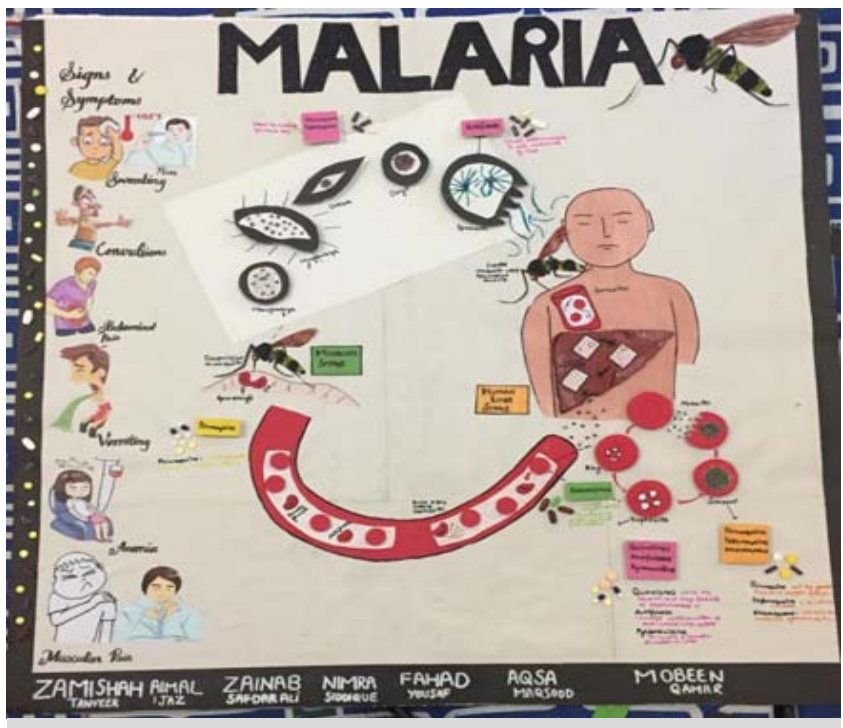

Teacher's Approach (Chart 2)

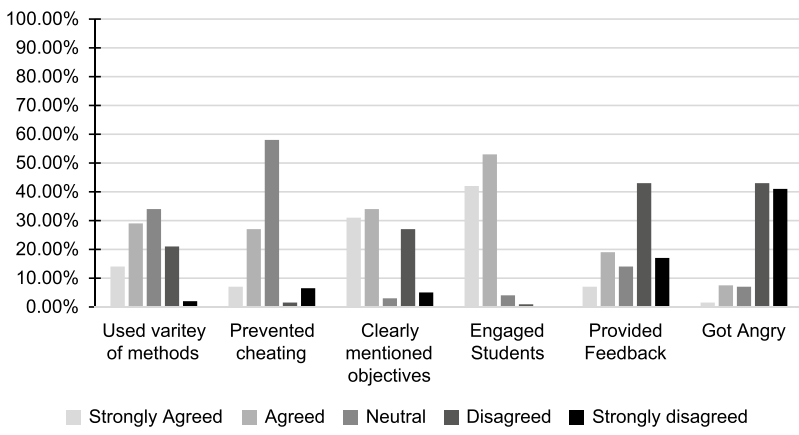

Figure-2. Teachers approach during the poster competition according to students' response on questionnaire (Cont.)

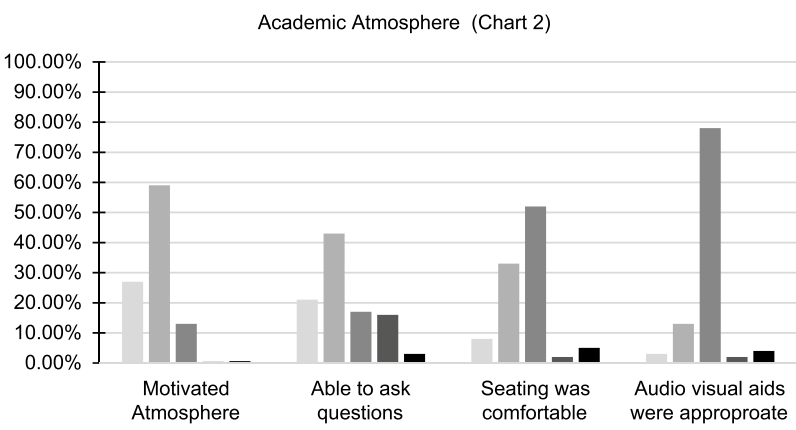

Strongly Agreed $\square$ Agreed $\square$ Neutral $\square$ Disagreed $\square$ Strongly disagreed

Figure-4. Academic Atmosphere during the poster competition according to students' response on questionnaire (Cont.)

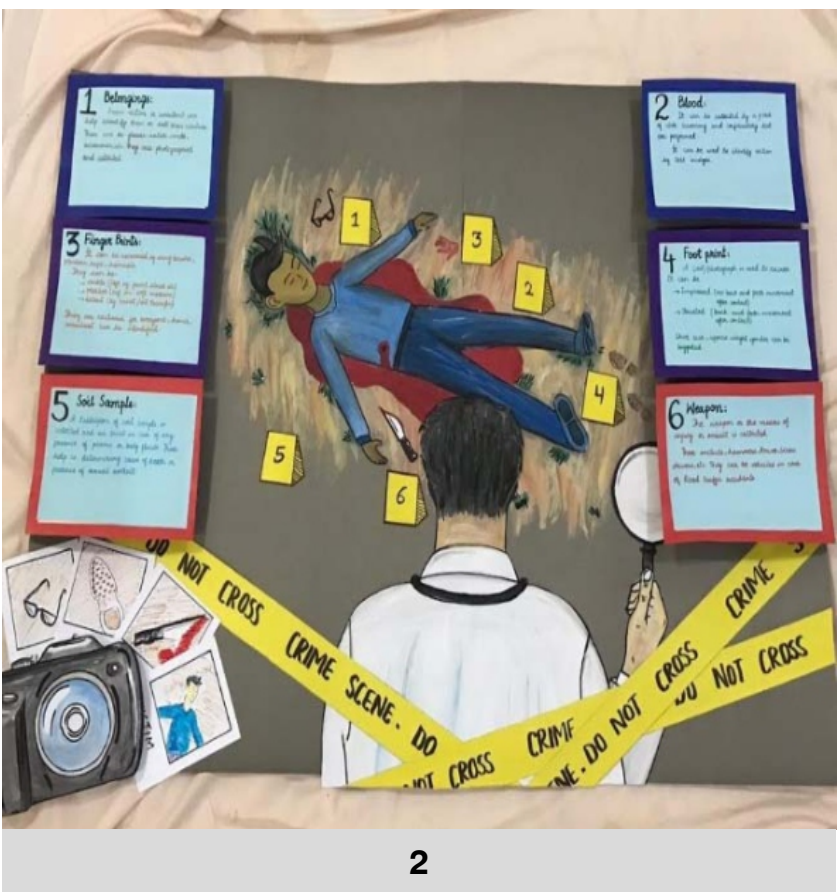




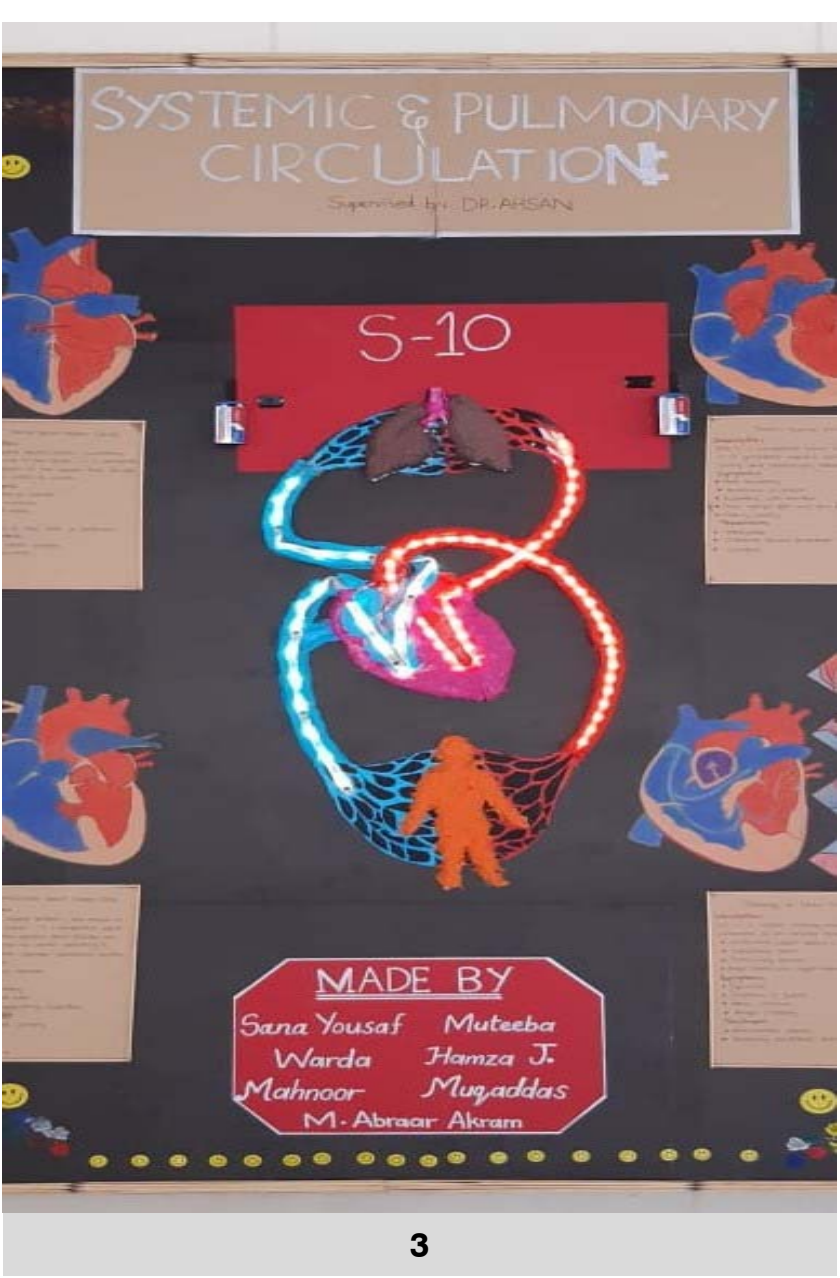

\section{DISCUSSION}

This study was done to assess effect of poster competition as a new learning methodology in basic medical sciences. Most definitely, students valued the poster rivalry as a method of learning. This finding is as per past study led by Vikas Seth et $\mathrm{al}^{8}$ where major part of students favored poster presentations. Albeit previous studies have derived that conventional board technique is better than this strategy, an investigation has brought up that in power point presentations the capacity to incorporate the content and the photos and pictures is an extraordinary favorable position and improves the educative estimation of the subject. ${ }^{9}$ It is additionally recommended that in spite of the fact that PowerPoint has a few preferences, it decreases the intuitive conversation among instructor and students. ${ }^{10}$ However, this technique maintained a strategic distance from the issue of the poor handwriting and less appealing writing board. These findings are as per past studies. ${ }^{11-15}$ In the current study, students additionally gave proposals and suggestions like consideration of interactive classes and case based learning. Subsequently, various reactions from the students will undeniably help instructors to adjust the educational plan and improvise themselves in instructing.

Majority of the students $81.25 \%$ (325) understood the topic well while using poster competition as learning tool. $55.75 \%$ (223) of all the students preferred group activity during poster competition. Our findings were also consistent with Moneyham et al., $1996 .{ }^{16}$ But on the contrary $62.25 \%$ (249) of the students were neutral in the view of increase in confidence due to poster competition. The main reason for this is that not all the 400 students were involved in presentation of their posters during the competition. Only one person from each group was presenting their respective posters. $48 \%$ (192) of all the students were of the view that such presentations will help them prepare better in future for post-graduation presentations. A very high percentage of the students (85.25\%) enjoyed the process of preparing the posters. Rowe et al., 2009 also found the same in there study. Students of Sahiwal Medical College also preferred such competitions to be held in the future as well (75.25\%). However the concept of using poster presentation as an additional benefit to traditional lecture was given mixed response by the students as $39.25 \%$ were against and $44.25 \%$ were in favor of this concept. Thirunavukkarasu et al., 2011 opposed our findings. ${ }^{17}$

Any new learning methodology cannot be adapted if teachers are not involved. Their guidance always is one of the major factors in recognition of such method. So as far as the approach of teachers of Sahiwal Medical College Sahiwal is concerned during this poster competition, majority of the students (strongly agreed + agreed > $70 \%$ ) appreciated the teacher's involvement in competition in various aspects. More than $65 \%$ of the students agreed that the teachers were able to stimulate their interest, managed time well and encouraged discussion during the poster competition (Figure-1). They were also of the 
view that teachers were organized, enthusiastic and demonstrated the topic of their respective posters very well (Figure-1). Our finding are consistent with those of Chaffee et,al., 2013. (18)

In a response to questions of usage of variety of methods and prevention of cheating during competition majority of the students (> 50\%) were neutral or not agreed. So these parts need improvement in future (Figure-2).

Students were also asked in questionnaire about the atmosphere during the competition. They felt that the atmosphere was relaxed and they were able to concentrate well during the competition (more than 70\%). Session was also well timed according to students' response (Figure-3). They felt motivated during the activity (more than $80 \%$ ). They were able to ask questions whenever they needed (Figure-4).

Students who finished the poster as learning mediation essentially better performed as referenced in the appraisal. This would infer that these posters can possibly encourage the move of authentic information when added to conventional lectures. This study in this manner affirms that there is included instructive incentive in joining poster learning with regular lectures as a major aspect of a mixed learning approach in basic medical sciences. This idea is upheld by the discoveries of Allen et $\mathrm{al}^{19}$, who indicated that including electronic intuitive instructional strategies, which enhanced customary talks, fundamentally improved students' execution. By sticking to these teaching hypotheses/standards during improvement, students' consideration was centered on the significant points by the connected portrayal and visual delineation of various components of various subjects. ${ }^{20}$ Students learn better when comparing words and pictures are introduced all the while as opposed to progressively by transient contiguity standard. ${ }^{21}$

Poster exhibition is enticing more widespread day by day as a stage for spreading knowledge. ${ }^{22}$ For a poster presentation to be fruitful, it must be done fastidiously and completely. ${ }^{23}$ The Posters gave clearness in their comprehension of ideas preparing them to fix them in their long haul memory. ${ }^{24}$ Posters make the way toward learning basic medical sciences subject progressively beautiful, fascinating, and alluring. It made mindfulness about the point among the students, which is emphatically expected to move them to learn and comprehend the point all the more obviously and in this way urge them to have a more extensive views of the subjects of basic medical sciences. A very much appealing Poster can excite the contemplations of students and make an ineradicable engraving on their psyches. ${ }^{25}$ Posters' creation conveys a spot to guide one's ability and helps one to decipher a scholarly picture or piece of information into mortal fact. Poster creation gives an occasion to demonstrate their ability, capability, information and nuance. ${ }^{26}$

Toward the finishing of the Posters presentation, students are loaded up with a feeling of achievement and this lifts their self-confidence. ${ }^{27}$ Students likewise need to build up the flexibility for group work and camaraderie during this activity. Instructors everywhere throughout the world have now understood that it is a student-focused realizing, which gives a great milieu, wherein they are inspired by close to personal contribution in the activity. ${ }^{28}$ In this poster exercise, they needed to work in a gathering setting. This finding affirms the conviction that when students are given a reasonable event and incited to advise themselves, they would create freedom, innovativeness and this would support their fearlessness. ${ }^{29}$ In our study, the students performed better in poster exercise which is in accordance with previous study by Samuel LJ et al. ${ }^{30}$ The feedback from our study was encouraging and positive. Many students felt that horizontal integration of Poster exercise with lectures. The study findings could be applied to the wider community of medical students as the study was done among medical students of $1^{\text {st }}$ year to $4^{\text {th }}$ year in departments of Basic medical sciences.

The major limitations of this current study were that the study period was too short, the concept of long-term knowledge retention after the use of poster exercise was not assessed. 


\section{CONCLUSION}

The outcomes of the current study propose that concepts distributed in the way of Poster competition may increase student's aptitude to evoke info, in spite of not meaningfully influencing students' performance. Nevertheless, more studies with greater student cohorts are necessary. Copyright $(03$ July, 2020.

\section{REFERENCES}

1. Lowe, C.I., J.L. Wright, and D.R. Bearn, ComputerAided Learning (CAL): An effective way to teach the index of orthodontic treatment need (IOTN)? J. Orthod, 2001; 28(4): 307-311.

2. Fall L, Berman N, Smith $\mathrm{S}$, et al. Multi-institutional development and utilization of a computer-assisted learning program for the pediatric clerkship: The CLIPP project. Acad Med. 2005; 80(9):847-55.

3. Sklar B. Introduction to online CME. Fam Pract Manag, 2003; 10(3):59-60.

4. Greenhalgh T. Computer assisted learning in undergraduate medical education. BMJ, 2001; 322(7277):40-4.

5. Gordon J, Oriol N, and Cooper J. Bringing good teaching cases "to life": A simulator-based medical education service. Acad Med, 2004; 79(1):23-7.

6. Knowles M. Self-directed learning: A guide for learners and teachers. New York: Association Press,1975.

7. Brandt $M$ and Davies $E$. Visual-spatial ability, learning modality and surgical knot tying. Can J Surg, 2006; 49(6):412-6.

8. Rowe N, llic D. What impact do posters have on academic knowledge transfer? A pilot survey on author attitudes and experiences. BMC Med Educ, 2009; 9:71.

9. Pelletier D. The focused use of posters for graduate education in the complex technological nursing environment. Nurse Educ Today, 1993; 13(5):382-8.

10. Boullata Jl, Mancuso CE. A "how-to" guide in preparing abstracts and poster presentations. Nutr Clin Pract. 2007; 22(6):641-6.

11. Taggart HM, Arslanian C. Creating an effective poster presentation. Orthop Nurs. 2000; 19(3):47-9,52.
12. Bhuiyan PS, Rege NN, Supe ON. Learning and motivation. In: Parkar SR, Shah F, editor. The Art of Teaching Medical Students. Chapter 6. Maharashtra: Medical Education Technology Cell, Seth G.S. Medical College and KEM Hospital.

13. Samuel LJ, Bandodkar LV, Rataboli PV. Poster and model competition: a novel interest-generating teaching tool in the subject of pharmacology. Int $\mathrm{J}$ Basic Clin Pharmacol 2014; 3:649-55.

14. Vikas Seth, Prerna Upadhyaya1, Mushtaq Ahmad, Virendra Kumar., Impact of various lecture delivery methods in pharmacology. EXCLI Journal, 2010; 9:96101.

15. Mayer, Richard E.; Anderson, Richard B. The instructive animation: Helping students build connections between words and pictures in multimedia learning. J Edu Psych, 1992; 84(4):444-452.

16. Moneyham L, Ura D, Ellwood S, Bruno B. The poster presentation as an educational tool. Nurse Educ, $1996 ; 21(4): 45-7$

17. J. Thirunavukkarasu, K. Latha, C. Sathish Babu, C.B. Tharani. A Study on effectiveness of different teaching methodology in pharmacology for under graduate students. Asian J Exp Biol Sci, 2011; 2(3):487-492.

18. Chaffee $H$. Ten talents of a model maker. Available from: http://www.Model maker.org, http://www.serc. carleton.edu/ introgeo/models/. [Last accessed on 2013 Apr 22].

19. A Garg, PV Rataboli, K Muchandi. Students' opinion on the prevailing teaching methods in pharmacology and changes recommended. Indian $\mathrm{J}$ Pharmacol, 2004; 36(3):155-158.

20. Rashmi Sharma, Ujala Verma, Bhuvneshwar Kapoor, V.S. Chopra., Novel teaching approaches in pharmacology. JK Science, 2004; 6(3):172-173.

21. Nilesh Chavda, Preeti Yadav, Mayur Chaudhari, N. D. Kantharia. Second year students' feedback on teaching methodology and evaluation methods in Pharmacology. National Journal of Physiology, Pharmacy and Pharmacology, 2011; 1:23-31.

22. Usha Adiga, Sachidananda Adiga. Case based learning in biochemistry. Int $\mathrm{J}$ Pharma and Bio Sci, 2011; 2(2):332-336.

23. Dinesh K. Badyal, Suman Bala, Prashant Kathuria. Student evaluation of teaching and assessment methods in pharmacology. Indian J Pharmacol, 2010; 42(2):87-89. 
24. Karaksha, A., et al., Development and Evaluation of Interactive Pharmacology Teaching Tools in Arabic Vs English, in International Conference on Education, Research and Innovation (ICERI). Madrid, Spain, 2010; 2700-2708.

25. Adams, A.M., Pedagogical underpinnings of computer based learning. J Adv Nurs, 2004; 46(1):512.

26. Mayer, R.E, R. Moreno, Nine ways to reduce cognitive OAD in multimedia learning. Educational Psychologist, 2003; 38(1):43-52.

27. Moore LW, Augspurger P, King MO, Proffitt C. Insights on the poster preparation and presentation process. Appl Nurs Res. 2001; 14(2):100-104.
28. Hardicre J, Coad J, Devitt P. Ten steps to successful conference presentations. Br J Nurs, 2007; 16(7):402404.

29. Crooks DL, Kilpatrick M. In the eye of the beholder: Making the most of poster presentations - Part 2. Can Oncol Nurs J, 1998; 8:154-159.

30. Brodsky L. In: Whaler PG, editor. Why model? Professional model making, history, practice, tips, tricks and thinking loud. Saturday Aug 21, 2010. Available from: http://www.promodelmaking.wordpress. com. [Last accessed on 2013 Nov 11].

\begin{tabular}{|c|c|c|c|}
\hline \multicolumn{4}{|c|}{ AUTHORSHIP AND CONTRIBUTION DECLARATION } \\
\hline Sr. \# & Author(s) Full Name & Contribution to the paper & Author(s) Signature \\
\hline 1 & Zahid Kamal Siddiqui & Title, Idea, Introduction. & \\
\hline 2 & Nauman Aziz & Biostatistics. & \\
\hline 3 & Raees Abbas Lail & Method and materials & \\
\hline 4 & Hafiza Swaiba Afzal & Discussion. & \\
\hline $\begin{array}{l}5 \\
6\end{array}$ & $\begin{array}{l}\text { Rana Aamir Diwan } \\
\text { Muhammad Amjad }\end{array}$ & $\begin{array}{l}\text { Conclusion and } \\
\text { recommendation. } \\
\text { References }\end{array}$ & \\
\hline
\end{tabular}

